NOTA TÉCNICA:

\title{
INSPEÇÃO TÉCNICA DE TRATORES E PULVERIZADORES UTILIZADOS EM PULVERIZAÇÃO AGRÍCOLA
}

MarçaCElizandro Dornelles², José Fernando Schlosser ${ }^{3}$, Walter Boller ${ }^{4}$, Alexandre Russini ${ }^{5}$, André Luis Casali ${ }^{6}$

\begin{abstract}
RESUMO
Os projetos de inspeção de tratores e pulverizadores são realizados já a longo tempo. Estes projetos buscam obter informações sobre a qualidade dos equipamentos em uso nas pulverizações agrícolas. As inspeções fundamentam-se na necessidade de que aplicações sejam eficientes evitando contaminações desnecessárias do ambiente, seres humanos e animais. Objetivou-se com este trabalho, realizar inspeção e levantar informações sobre o estado de conservação dos pulverizadores e tratores na Depressão Central do Estado do Rio Grande do Sul. Durante a inspeção, foram avaliados os itens: manômetros, depósito de calda, filtros, bicos de pulverização, itens de proteção e segurança e verificações sobre o trator. Houve classificação das máquinas em aprovação, reprovação parcial ou reprovação. Foram inspecionados 84 pulverizadores e 75 tratores. Apenas 4 pulverizadores (4,8 \%) foram aprovados, sendo a principal causa de reprovação, o tempo de uso. Os pulverizadores autopropropelidos tiveram maior aprovação. A metodologia foi eficiente, permitindo inspeção rápida e abrangente.
\end{abstract}

Palavras-chave: pulverização, máquinas agrícolas, manutenção

\section{ABSTRACT}

\section{TECHNICAL INSPECTION OF TRACTORS AND SPRAYERS USED IN AGRICULTURAL SPRAYING}

The projects of tractors and sprayer's inspections are accomplished for a long time. These projects aiming to get information about the quality of the machines involved in agrochemical's application. The inspections are important due the need that any application be efficient avoiding contaminations of environmental, peoples and animals. Then, it was accomplished this research with objective to do inspection and get information on the operation conditions and use of sprayers and tractors in the Central Region of Rio Grande do Sul State. During the inspection it was evaluated the items: manometers, tank, filters, spraying nozzles, safety items, and tractor items. The machines were classified as approved, approved with restrictions and disapproved. It was inspected 84 sprayers and 75 tractors. Only four sprayers (4.8\%) were approved, and the number of the disapproved sprayers was positively related to the machinery age. The self propelled sprayers were the most approved machine. The methodology was efficient allowing fast and comprehensive inspection.

Keywords: spraying, agricultural machines, maintenance

\section{Recebido para publicação em 31/05/2010. Aprovado em 08/09/2010.}

1- Extraído da dissertação de Mestrado do primeiro autor

2- Eng. Agrônomo, Msc., NEMA-UFSM. Santa Maria, RS. Email: dornellesagro@gmail.com

3- Eng. Agrônomo, Dr., Prof Titular, DER-UFSM, Santa Maria/RS. Email: schlosse@ccr.ufsm.br

4- Eng. Agrônomo, Dr., Prof. Titular, PPAGRO-UPF, Passo Fundo/RS. Email: wboller@upf.br

5- Eng. Agrônomo, Msc. PPGEA-UFSM. Santa Maria/RS. Email: Alexandrerussini@hotmail.com.

6- Eng. Agrônomo, Mestrando, PPGEA-UFSM. Santa Maria/RS. Email: andrcasali@yahoo.com.br 


\section{INTRODUÇÃO}

Os agrotóxicos são fundamentais para o sucesso e incremento da produção alimentar mundial por meio da proteção dos cultivos agrícolas (CUNHA, 2008). Entretanto essa classe de insumos é alvo de atenção devido às conseqüências negativas que podem causar ao meio ambiente, exigindo cada vez mais conhecimento por parte do aplicador (CUNHA; RUAS, 2006). Além disso, os operadores de máquinas agrícolas estão constantemente sujeitos a elevados níveis de ruído, poeira, posições anti-ergonômicas e contaminação por agrotóxicos (SCHLOSSER et al., 2002), sendo esse último um dos graves problemas de saúde mundial, principalmente em países em desenvolvimento (KONRADSEN et al., 2003). No Brasil, estima-se que das 15 milhões de pessoas expostas ao trabalho rural aproximadamente 150 mil a 200 mil delas sofrem intoxicações agudas a cada ano, devido ao contato inadequado com defensivos agrícolas (GARCIA; ALVES FILHO, 2005).

Muitas destas intoxicações se devem a condições inadequadas de uso das máquinas utilizadas para pulverização dos agrotóxicos. A preocupação com a técnica de aplicação do agrotóxico geralmente é preterida em relação à escolha do insumo, ocasionando perdas ou ineficácia em sua aplicação (CUNHA; RUAS, 2006). Nesse sentido, o desenvolvimento de tecnologias de aplicação busca melhoria da qualidade de aplicação pela redução da contaminação ambiental, deriva, volume de calda, visando aplicação da dosagem planejada conforme o tipo de ponta de pulverização e à pressão de trabalho (BAESSO et al., 2009; MAZIERO et al., 2009).

De acordo com Dornelles et al., (2009), as aplicações de agrotóxicos em culturas de grãos são feitas predominante por pulverizadores hidráulicos de barras. Essas máquinas devem estar sempre em condições de uso adequadas para proporcionar operações eficientes, de modo a ser respeitado o prazo agronômico ótimo, fator de sucesso para cada operação agrícola (BORGES et al., 2006). Os tratores agrícolas também devem apresentar condições de uso adequadas, pois é fonte de potência e propulsão aos pulverizadores agrícolas (ABUHAMDEH; AL-JALIL, 2004).

Uma medida adotada inicialmente em alguns países europeus para garantir a qualidade das máquinas de aplicação de agrotóxicos é a "inspeção periódica de pulverizadores agrícolas". Nesses países, são realizadas inspeções de pulverizadores desde a década de 1940. Em contrapartida, no Brasil, estudos mostraram a precariedade das máquinas pulverizadoras em algumas regiões (BORGHI et al., 2003; SANTOS; MACIEL,
2006). Diante da importância da utilização adequada das máquinas utilizadas nos processos de aplicação de agrotóxicos, objetivou-se, com este trabalho, implantar um projeto de inspeção técnica e realizar diagnóstico sobre o estado de conservação e uso dos pulverizadores e tratores agrícolas utilizados na região da depressão central do estado do Rio Grande do Sul.

\section{MATERIAL E MÉTODOS}

A área de abrangência do projeto foi a região da Depressão Central do Rio Grande do Sul totalizando 28 municípios pertencentes a região, onde 17 desses fizeram parte do projeto (FEE, 2007). A equipe percorreu rodovias e estradas da região de forma aleatória, sendo que os agricultores participaram voluntariamente do projeto. A forma de acesso as máquinas ocorreu de duas maneiras: a primeira foi através de visitas às propriedades sem prévio aviso e a segunda por contatos realizados pelos proprietários, após tomar conhecimento do projeto por uma das formas de divulgação (folhetos, notas de imprensa, revendas de máquinas agrícolas, cooperativas, etc.).

Ao abordar o operador houve apresentação da equipe e do projeto, em seguida foi feita simulação da última aplicação para proceder à inspeção. As avaliações foram divididas em: dados identificatórios, manômetro, bicos de pulverização, filtros, depósito, proteção e segurança e verificações sobre alguns aspectos de segurança na operação do trator agrícola durante a pulverização. Para facilitar as inspeções foi elaborado questionário que contemplou as informações necessárias. Os pulverizadores foram divididos em três classes quanto à fonte de potência e acoplamento: máquinas de engate aos três pontos do sistema hidráulico, máquinas com engate de arrasto (barra de tração) e pulverizadores autopropelidos. Houve classificação quanto ao tempo de uso das máquinas em 4 classes conforme o Quadro 1.

Após a inspeção houve classificação conforme metodologia obtida a partir de Gracia e Val (2001). A classificação foi dividida em 3 classes, uma classe para pulverizadores que atenderam critérios mínimos exigidos (Quadro 2), havendo aprovação das máquinas. Uma segunda classe onde foram detectadas não conformidades, consideradas como leve, assim denominou-se essa classe de máquinas com aprovação parcial e uma terceira classe onde foram observadas não conformidades classificadas como graves por facilitar poluição do meio ambiente ou do operador e também por afetar a eficiência do processo de pulverização em análise. 
Os pulverizadores ou tratores que apresentaram uma ou mais não conformidades em relação ao Quadro 2, foram analisados conforme o Quadro 3.

Para o verificação da precisão de leitura do manômetro foi desenvolvida uma bancada de testes (Figura 1).

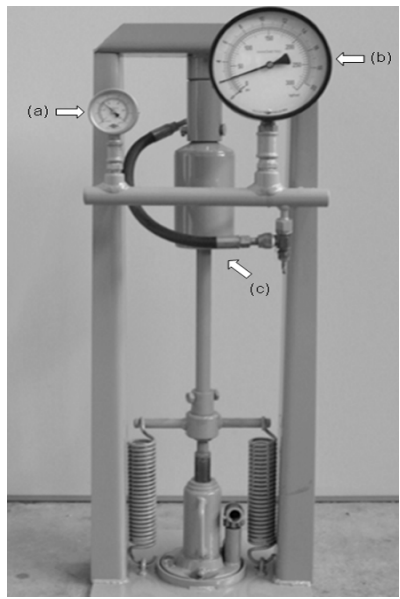

Figura 1. Instrumento de aferição ((a) manômetro em teste, (b) manômetro aferido e (c) sistema de pressão hidráulica).
Assim, após conexão do manômetro em uso nos pulverizadores sobre o instrumento de teste, estes foram submetidos a 4 diferentes valores de pressões do sistema (196, 392, 588 e $784 \mathrm{kPa})$. Langenakens e Pieters (1998) sugerem que são inaceitáveis valores superiores de erros acima de $\pm 10,0 \%$ sobre valores verificados em manômetros de precisão aferidos.

Para a determinação da precisão dos manômetros foi utilizada a Equação 1.

$E p=\frac{(P m-P M)}{P M} \times 100$

em que,

Ep $=$ erro de leitura de pressão para o manômetro em uso no pulverizador (\%);

$\mathrm{Pm}=$ pressão determinada pelo manômetro em uso no pulverizador $(\mathrm{kPa})$;

$\mathrm{PM}=$ pressão determinada pelo manômetro de precisão $(\mathrm{kPa})$; e

$100=$ fator de conversão de valores (de decimal para porcentagem).

Quadro 1. Faixas de classificação das máquinas quanto ao tempo de uso (anos)

\begin{tabular}{ccccc}
\hline Faixa de idade & Até 5 anos & De 5 a 10 anos & De 10 a 15 anos & Maior do que 15 anos \\
\hline Classe & 1 & 2 & 3 & 4 \\
\hline
\end{tabular}

Quadro 2. Conformidades mínimas exigidas sobre pulverizadores e tratores agrícolas (Adaptado a partir de Gracia e Val, 2001)

\begin{tabular}{ll}
\hline \multirow{2}{*}{ Depósito } & - Tampa de fechamento e válvula de drenagem presentes e em bom estado \\
& - Indicador de nível de calda em bom estado e com escala visível \\
& - Ausência de fugas de calda \\
\hline \multirow{3}{*}{ Manômetro } & - Diâmetro externo igual ou maior do que $63 \mathrm{~mm}$ \\
\hline \multirow{2}{*}{ Filtros } & - Manômetro sem perdas de glicerina \\
& - Bom funcionamento (precisão de até $\pm 10 \%$ em bancada de teste) \\
\hline \multirow{3}{*}{ Bicos e pontas } & - Presença de filtros no bocal do depósito de calda, bomba e em linhas \\
& - Filtros limpos e com malhas em bom estado \\
\hline \multirow{2}{*}{ Proteção e } & - Desgaste menor do que $\pm 10 \%$ em relação a média da barra de pulverização \\
segurança & - Ausência de obstruções e fugas sobre portabicos ou pontas de pulverização \\
& - Dispositivos antigotejo presentes e em bom estado \\
\hline & - Proteção correta da tomada de potência (TDP) e junta cardânica \\
& - Proteção correta de correias e polias \\
& - Proteção correta do eixo livre da bomba \\
Trator agrícola & - Ruído aceitável ao nível do ouvido do operador (menor do que 85 dB) \\
& - Presença de estrutura de proteção contra o capotamento(EPCC)e toldo solar embom estado \\
& - Tratômetro e acelerador manual em bom estado \\
& - Rotação da tomada de potência (erro menor ou igual a \pm 5\%) \\
& - Proteção da tomada de potência em bom estado de conservação
\end{tabular}


Quadro 3. Descrição de não conformidades leves sobre pulverizadores e tratores agrícolas (Adaptado a partir de GRACIA; VAL, 2001)

\begin{tabular}{|c|c|}
\hline Depósito & $\begin{array}{l}\text { - Fechamento da tampa deficiente } \\
\text { - Indicador de nível de calda ilegível e/ou sem escala } \\
\text { - Restos de produtos externamente } \\
\text { - Fugas de calda em gotejamento }\end{array}$ \\
\hline Manômetro & $\begin{array}{l}\text { - Diâmetro da circunferência externa do manômetro inferior a } 63 \mathrm{~mm} \\
\text { - Perdas de glicerina (nível menor do que } 3 / 4 \text { do volume total) } \\
\text { - Esfera do manômetro sujo } \\
\text { - Funcionamento com erro além do tolerado }( \pm 10 \%)\end{array}$ \\
\hline Filtros & $\begin{array}{l}\text { - Filtros com resíduos } \\
\text { - Fugas em gotejamento ou escorrimento }\end{array}$ \\
\hline Bicos e pontas & $\begin{array}{l}\text { - Pontas com desgaste excessivo ou obstruídas } \\
\text { - Um ou mais dispositivos antigotejo inexistentes ou deteriorados } \\
\text { - Fugas nos bicos ou condução hidráulica, sem gotejos contínuos }\end{array}$ \\
\hline $\begin{array}{l}\text { Proteção e } \\
\text { segurança }\end{array}$ & $\begin{array}{l}\text { - Dispositivo de proteção da TDP e junta cardânica ineficiente } \\
\text { - Proteção insuficiente de correias e polias } \\
\text { - Ausência de proteção do eixo livre da bomba } \\
\text { - Depósito de água limpa }\end{array}$ \\
\hline Trator agrícola & $\begin{array}{l}\text { - Ruído ao ouvido do operador excessivo (maior do que } 85 \text { dB) } \\
\text { - Presença de EPCC e/ou proteção solar ao operador danificada } \\
\text { - Tratômetro e/ou acelerador manual danificado } \\
\text { - Rotação da tomada de potência (erro maior do que } \pm 5 \% \text { ) }\end{array}$ \\
\hline
\end{tabular}

A rotação da tomada de potência do trator ou pulverizador autopropelido, foi medida com tacômetro de precisão (especificar mais o tacômetro, por exemplo, modelo e resolução) posicionado sobre o centro do eixo de acionamento da tomada de potência ou eixo livre da bomba de pressão. De posse dos valores de rotação padrão de cada bomba de pressão sobre os pulverizadores, foi calculado o erro de rotação para cada conjunto inspecionado (Equação 2).

$$
E r=\frac{(r-R)}{r} \times 100
$$

em que,

$\mathrm{Er}=$ erro de rotação $(\%)$;

$\mathrm{r}=$ velocidade angular medida $\left(\mathrm{r} \mathrm{min}^{-1}\right)$;

$\mathrm{R}=$ velocidade angular padrão exigida pela bomba de pulverização $\left(\mathrm{r} \mathrm{min}^{-1}\right)$; e

$100=$ fator de correção de decimal para porcentagem.

Nesse caso, as máquinas não foram classificadas como inaptas, porém, as não conformidades, classificadas como leves devem ser corrigidas para aprovação futura.

No Quadro 4 são descritas as faltas consideradas como graves as quais reprovam as máquinas ao uso devido à criticidade ou por prejudicar diretamente o rendimento operacional.

Assim, após a inspeção e classificação das máquinas, houve georeferenciamento do local onde foi feita a inspeção e etiquetagem indicando o número do pulverizador para posterior cadastro sendo que, máquinas aprovadas, reprovadas parcialmente e reprovadas ao uso receberam etiquetas com cor de fundo verde, amarelo e vermelho, respectivamente.

\section{RESULTADOS E DISCUSSÃO}

Ao todo foram avaliadas 82 propriedades e inspecionados 84 pulverizadores e 75 tratores agrícolas em 16 municípios da região. Quanto ao tempo de uso, $36,9 \%$ e $59,5 \%$ dos pulverizadores e tratores, respectivamente, possuíam mais do que 15 anos (Figura 2). 
Quadro 4. Descrição de não conformidades graves sobre pulverizadores e tratores agrícolas (Adaptado a partir de GRACIA; VAL, 2001)

\begin{tabular}{|c|c|}
\hline Depósito & $\begin{array}{l}\text { - Ausência de tampa de fechamento e/ou indicador de nível de calda } \\
\text { - Acúmulo de produtos no interior do tanque } \\
\text { - Fugas de calda contínuas }\end{array}$ \\
\hline $\begin{array}{l}\text { Manômetro e } \\
\text { regulador }\end{array}$ & $\begin{array}{l}\text { - Manômetro sem glicerina, inoperante ou ausente } \\
\text { - Escala do manômetro ilegível } \\
\text { - Funcionamento defeituoso do regulador ou com vazamentos }\end{array}$ \\
\hline Filtros & $\begin{array}{l}\text { - Inexistência de filtros no bocal, aspiração da bomba e/ou em linhas } \\
\text { - Filtros e/ou malhas de filtragem ausentes ou danificadas }\end{array}$ \\
\hline Bicos e pontas & $\begin{array}{l}\text { - Presença de pontas com desgaste excessivo } \\
\text { - Fugas de calda sobre um ou mais portabicos }\end{array}$ \\
\hline $\begin{array}{l}\text { Proteção e } \\
\text { segurança }\end{array}$ & $\begin{array}{l}\text { - Proteção da TDP e junta cardânica e/ou proteção de correias e polias } \\
\text { inexistentes } \\
\text { - Ausência de proteção do eixo livre da bomba }\end{array}$ \\
\hline Trator agrícola & $\begin{array}{l}\text { - Ruído ao ouvido do operador excessivo } \\
\text { - Ausência de EPCC e/ou proteção solar ao operador } \\
\text { - Tratômetro e/ou acelerador manual ausente }\end{array}$ \\
\hline
\end{tabular}

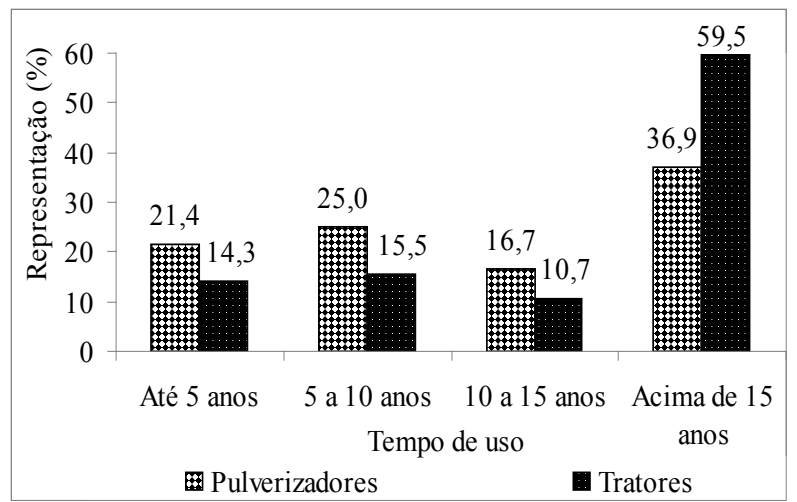

Figura 2. Classificação de tratores e pulverizadores quanto ao tempo de uso (anos).

Para a frota de tratores, apenas $14,3 \%$ das máquinas apresentaram tempo de uso de até 5 anos (Classe 1). O tempo médio de uso foi de 16,8 anos, sendo que mais de $70 \%$ dos tratores estiveram acima do tempo de uso máximo recomendado de 10 anos, concordando com Debiasi et al. (2004). Assim, é possível afirmar que os tratores utilizados em atividades de pulverização são máquinas com elevado tempo de uso dentro da propriedade. Quanto aos pulverizadores, $21,4 \%$ apresentaram até 5 anos e $36,9 \%$ com tempo de uso acima de 15 anos. O tempo médio de uso foi de 17,4 anos, determinando envelhecimento da frota de máquinas aplicadoras de agrotóxicos na região.

Destaca-se a ausência de proteção da TDP como item de maior reprovação. Mesmo sendo item de grande periculosidade, o órgão de proteção esteve ausente em 53,6 \% dos pulverizadores, proteção ineficiente em 38,1 \% e proteção correta em apenas $8,3 \%$ das máquinas. Em segundo lugar na ordem de itens não conformes, os manômetros apresentaram padrão mínimo de funcionalidade em precisão de leitura, nível de glicerina e diâmetro externo da esfera em apenas 19,0 \%. Cruciais para a calibração do pulverizador, estes equipamentos merecem maior atenção e sua ausência pode explicar a ineficiência de muitas aplicações. O uso de rotação adequada da TDP para acionamento dos pulverizadores foi constatado em apenas 20,2 \% das máquinas. Em quarto e quinto lugares, a estrutura de proteção contra capotamento (EPCC) e a ausência de vazamentos foram constatadas em apenas $35,7 \%$ das máquinas inspecionadas.

Assim, conforme a metodologia de classificação foi determinada aprovação de uso em apenas 4 pulverizadores $(4,8 \%)$, e 29 pulverizadores $(34,5 \%)$ apresentaram não conformidades leves (reprovação parcial). Os pulverizadores reprovados contabilizaram 60,7\%. Na Espanha, Gracia e Val (2001), citam que apenas $5,3 \%$ dos pulverizadores 
Quadro 5. Aprovação de itens inspecionados sobre tratores e pulverizadores

\begin{tabular}{lc}
\hline Descrição & Aprovação (\%) \\
\hline Proteção da TDP e junta cardânica & 8,3 \\
Precisão de manômetros & 19,0 \\
Rotação da TDP (erro menor ou igual a \pm 5\%) & 20,2 \\
Ausência de vazamentos (fugas de calda) & 35,7 \\
Estrutura de proteção contra capotamento & 35,7 \\
\hline
\end{tabular}

inspecionados foram reprovados.

Os pulverizadores com engate aos três pontos do sistema hidráulico foram aprovados em apenas 3,3 \% (Figura 3). A classe de pulverizadores com engate de arrasto apresentou $6,3 \%$ de aprovação. A classe de autopropelidos teve 14,3 \% de aprovação, $85,7 \%$ de reprovação parcial e nenhuma máquina foi reprovada, apresentando melhores condições operacionais e de segurança.

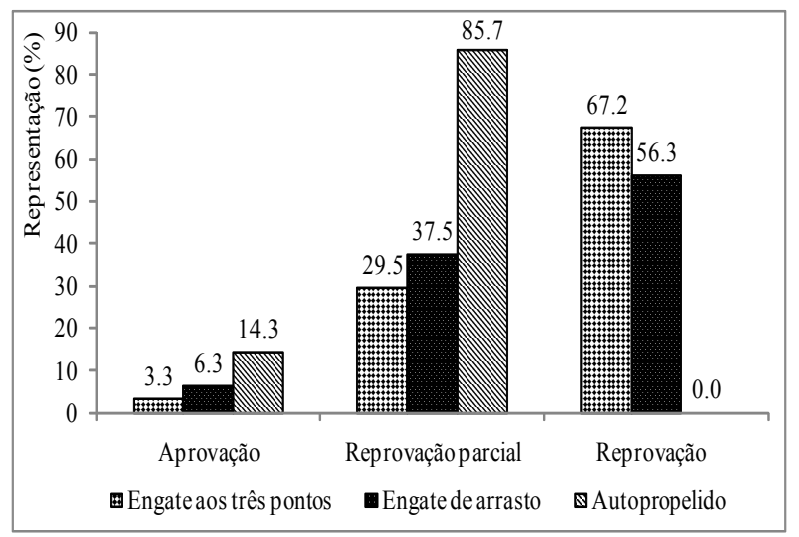

Figura 3. Classificação quanto ao tipo de pulverizadores inspecionados.

Quanto à classificação dos pulverizadores em relação ao tempo de uso (Figura 4), determinou-se que máquinas da classe 1 ( 0 a 5 anos) foram aprovadas em 12,0\%, a classe 2 apresentou 4,0\% de aprovação e as classes 3 e 4 (acima de 15 anos) não tiveram aprovação.

A classe 1 teve apenas 1 máquina reprovada $(2,0 \%)$, porém, as classes 3 e 4 tiveram reprovações em $84,6 \%$ e $86,2 \%$, respectivamente, colocando em risco o meio ambiente e os aplicadores envolvidos nos processos de pulverização. As máquinas com menor tempo de uso apresentaram melhores condições operacionais concordando com Gandolfo (2001). Assim, os resultados comprovam a necessidade de regularização dos projetos de inspeção de máquinas utilizadas nos processos de pulverização agrícola no Brasil.

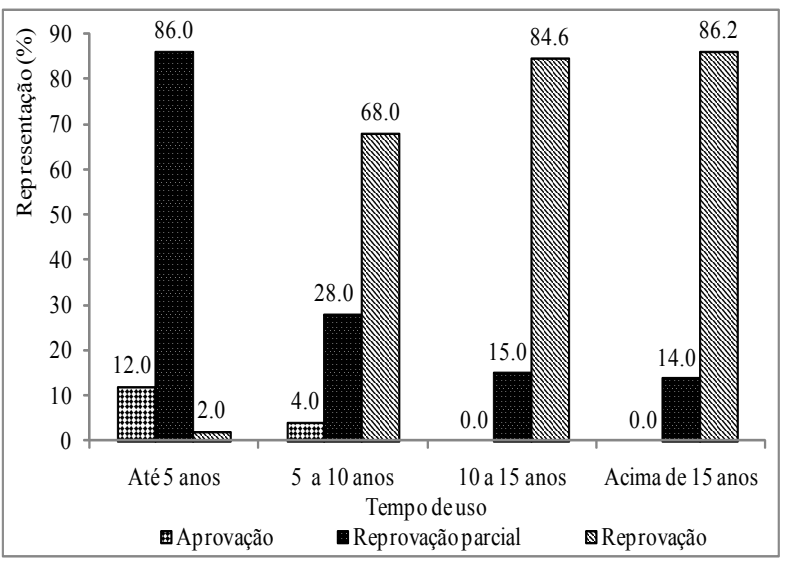

Figura 4. Classificação quanto ao tempo de uso dos pulverizadores inspecionados.

\section{CONCLUSÕES}

- A implantação do projeto de inspeção de pulverizadores agrícolas na região Central do Rio Grande do Sul teve grande êxito e a metodologia utilizada foi eficiente e abrangente;

- Não conformidades graves foram determinadas em 51 (60,7\%) pulverizadores;

- O índice de reprovação foi proporcional ao tempo de uso dos pulverizadores. Apenas 4 pulverizadores $(4,8 \%)$ foram considerados adequados para aplicação de agrotóxicos; e

- Pulverizadores autopropelidos apresentaram maior conformidade comparados aos pulverizadores sem fonte própria de potência. 


\section{AGRADECIMENTOS}

A Comissão de Aperfeiçoamento Pessoal de Ensino Superior pelo fomento estudantil.

Aos operadores e proprietários de tratores e pulverizadores agrícolas pelo apoio.

\section{REFERÊNCIAS BIBLIOGRÁFICAS}

ABU-HAMDEH, N.H.; AL-JALIL, H.F. Computer simulation of stability and control of tractor trailed implement combinations under different operating conditions. Bragantia, Campinas, v.63, n.1, p.149-162, 2004.

BAESSO, M.M. et al.; GOULART JUNIOR, R.; TEIXEIRA, M.M.; AUGUSTO, F.; RODRIGUES JUNIOR, F.A.; RUAS, R.A.A. Avaliação da uniformidade de distribuição volumétrica de bicos hidráulicos em pulverizador com assistência de ar. Engenharia na agricultura, Viçosa, v.17, n.2, p.120-127, 2009.

BORGES, I. O.; MACIEL, A.J.S.; MILAN, M. Programa computacional para o dimensionamento de colhedoras considerando a pontualidade na colheita de soja. Engenharia Agrícola, Jaboticabal, v.26, n.1, p.131-141, 2006.

BORGHI, E.; SCHREINER, R. C.; RAMOS, H. H.; PECHE FILHO, A.; YANAI, K. Qualidade de pulverizadores utilizados em pequenas propriedades. Engenharia Agrícola, Jaboticabal, v.23, n.1, p.113-121, 2003.

CUNHA, J.P.A.R. da; RUAS, R.A.A. Uniformidade de distribuição volumétrica de pontas de pulverização de jato plano duplo com indução de ar. Pesquisa Agropecuária Tropical, Goiânia, v.36, n.1, p.61-66, 2006.

CUNHA, J.P.A.R. da. Simulação da deriva de agrotóxicos em diferentes condições de pulverização. Ciência e Agrotecnologia, Lavras, v.32, n.5, p.1616-1621, 2008.

DEBIASI, H.; SCHLOSSER, J. F.; PINHEIRO, E. D. Características ergonômicas dos tratores agrícolas utilizados na região central do Rio
Grande do Sul. Ciência Rural, Santa Maria, v.34, n.6, p.1807-1811, 2004.

DORNELLES, M.E.C. de; SCHLOSSER, J.F.; CASALI, A.L.; BRONDANI, L.B. Inspeção técnica de pulverizadores agrícolas: histórico e importância. Ciência Rural, Santa Maria, v.39, n. 5, p.1600-1605, 2009.

FEE - Fundação de Economia e Estatística. Corede central. Porto Alegre, 2007. http:// www.fee.tche.br/sitefee/pt/content/resumo/ pg_coredes_detalhe.php? corede $=/$ central. 5 set. 2007.

GANDOLFO, M.A. Inspeção periódica de pulverizadores agrícolas. 2001. Botucatu: UNESP, 2001. 192p. (Tese de doutorado)

GARCIA, E.; ALVES FILHO, J.P. Aspectos de prevenção e controle de acidentes

no trabalho com agrotóxicos. São Paulo: Fundacentro, 2005. 53p.

GRACIA, C.; VAL, L. Informe final de actividades y resultados correspondientes al desarrolo del proyecto: Revisión de equipos de pulverización empleados em explotaciones que practican producción integrada. Informativo. Valência: UPV, 2001. 20p. (Informativo).

KONRADSEN, F.; VAN DER HOEK, W.; COLE, D.C.; HUTCHINSON, G.; DAISLEY, H.; SINGH, S.; EDDLESTON, M. Reducing acute poisoning in developing countries - options for restricting the availability of pesticides. Toxicology, Copenhagen, v.192, n.2, p.249-261, 2003

LANGENAKENS, J. \& PIETERS, M. Compulsory testing of sprayers in Belgium: Criteria and procedures for orchard sprayer. Agriculture Research Centre. 1998.

MAZIERO, H.; GUEDES, J.V.C.; FARIAS, J.C. RODRIGUES, R.B.; DALAZEN; G.; DAL PRÁ, E. Volume de calda e inseticidas no controle de Piezodorus guildinii (Westwood) na cultura da soja. Ciência Rural, Santa Maria, v.39, n.5, 2009. 
SANTOS, S.R. dos; MACIEL, A.J. da S. Proposta metodológica utilizando ferramentas de qualidade na avaliação do processo de pulverização. Engenharia Agrícola, Jaboticabal, v.26, n.2, p.627-636, 2006.
SCHLOSSER, J.F.; DEBIASI; H.; PARCIANELLO, G.; RAMBO, L. Caracterização dos acidentes com tratores agrícolas. Ciência Rural, Santa Maria, v.32, n.6, p.977-981, 2002. 